combine. Anatomy became the study of embalmed bodies and fixed tissues whereas pathology branched off and took with it most of the direct clinical applications, including the study of disease in the recently dead and the examination of fresh tissues for diagnosis. The deficiencies of learning surgery on cadavers became more obvious with rising technical standards in operating-anatomy was reduced to a mere preliminary.

The history of anatomy has been one long retreat from the age of Munro II until now. For the older generation there has been a gradual reduction in the share of the curriculum, in status, in salary (in common with other academics), and in the subject's links with clinical medicine. And each of these changes has been fought every inch of the way, in a rearguard action which was touching in some respects but ultimately wrong headed and doomed to failure.

Where does all this leave the anatomy lecturer embarking on a career in the subject? The problem has been that nostalgia for the past and fear of the future have combined to prevent anatomy making the kind of transition which has been successfully negotiated by physiology, the transition from being a subsidiary of clinical medicine to being a science in its own right. In failing to make this transition anatomy has severed teaching from research-tearing itself in two in the process.

In other words, teaching and research must move towards each other if the subject is to stay in one piece. This is the lesson of the past-viable science requires integration between a relevant teaching role and activity at the cutting edge of research if it is to remain happy and healthy.

This is one possibility. The alternative is a reinte- gration with medicine-perhaps with pathology - to restore not just relevance but also a clinical role. The administrative difficulties and staffing considerations of such change are certainly intimidating, especially in the current financial climate, and of course there would have to be a substantial evolution in the scope of the subject and its orientation, but it would certainly be invigorating.

I cannot see that the status quo is a viable long term option. There is still time to save anatomy, but it requires a willingness to change the nature of the subject; to reverse the destructive trends of two hundred years in favour of expansion and reintegration instead of contraction and fragmentation; to launch a pre-emptive strike instead of consolidating an entrenched resistance. At present, anatomy is just what has been left behind when the other (more interesting?) biological sciences have departed and set up shop independently. Leaving aside the ambitious ideal of clinical reintegration, the minimum formula for survival and success is simple, and yet difficult: more and better research and less and better teaching - the two are intimately linked.

Whether the subject can reform itself from within or whether constructive change can be stimulated from without, I do not know. Perhaps the forces of decline are too large or powerful. Perhaps I am simply being nostalgic even in thinking that anatomy should be saved. Maybe it has condemned itself? But the heady days of the Scottish Enlightenment suggest that there is some kind of broad intrinsic fascination in the subject which, if only it could be presented in a proper context, might restore anatomy to its place in the sun.

(Accepted 20 February 1991)

\title{
The physician scientist: an endangered but far from extinct species
}

\section{J Weatherall}

Although the recent revolution in the biological sciences offers such exciting prospects for medical research and practice, this is not reflected in the current mood of academic medicine, which is both confused and pessimistic about its future role. This identity crisis is exemplified in the fascinating book Osler's Legacy-The Department of Medicine at Johns Hopkins, 1889-1989, published to coincide with the centennial celebrations of that Mecca for clinical investigators.' For after a century of training physician scientists the department of medicine at Hopkins has changed its organisation and philosophy. In explaining why, John D Stobo, the tenth chairman of the department in succession to William Osler, writes:

"One principle guided the restructuring; the day of the renaissance physician was over. While the department, and therefore each division, must realise its responsibility in research, teaching, and clinical care, no single individual could be master of all three. Each division would, therefore, have as its director a person with a proven record of scholarship in basic science related to the particular clinical speciality."

Arguments of this kind are based on the assumption that most of the important medical advances of the future are likely to come from molecular and cell biology and related basic sciences and that because of their complexity it will no longer be possible for one person to be a competent clinician, teacher, and research worker. This view, argued most cogently by
Gill in his gloomy essay "The end of the physicianscientist?"' has been echoed by many other leaders of American academic medicine.

What has been happening in the United Kingdom while our American colleagues have been indulging in this soul searching? Not much it seems. Although the basic medical sciences were mentioned in the report of the House of Lords Select Committee on Science and Technology Priorities in Medical Research, ${ }^{3}$ the main thrust of its conclusions was directed at strengthening research in the NHS. And papers that have dealt with the staffing and reorganisation of the NHS have said next to nothing about research. Achieving a Balance described it as a skill to be acquired somewhere along the way, akin to passing a catheter; in Working for Patients ${ }^{5}$ it was dismissed in a sentence or two. But if we are to take advantage of the enormous potential for clinical practice that will stem from the molecular sciences and at the same time respond to the challenge to clinical research posed by the profound changes in the NHS, we too will have to examine the future pattern of research in our university clinical departments.

\section{Future development of medical research}

As the revolution in biology which has stemmed from the molecular sciences has been the equal of that in physics at the beginning of this century it is not surprising that the message that the molecular sciences
D I Weatherall, FRs, Nuffield professor of clinical medicine

$B M \mathcal{1} 1991 ; 302: 1002-5$
BMJ VOLUME 302

27 APRIL 1991 
hold the answer to everything has permeated academic medicine. How justified is this view?

The most immediate impact of the molecular sciences has been in clinical genetics, in which it has been possible to pinpoint the molecular defects in many genetic diseases and hence to improve their control. ${ }^{6}$ Molecular clinical genetics will continue to expand and should encompass the genetics of the common killers of Western society: coronary artery disease, stroke, major rheumatic disorders, psychoses, and so on. Once the products of the gene loci which determine susceptibility or resistance to these diseases are defined we should have a better understanding of how they arise and, hopefully, how to prevent or treat

\section{... molecular biology will enrich clinical practice.}

them. And as our new technology is applied to the neurosciences and developmental biology we may at last get to grips with chronic disorders of the nervous system and such intractable problems as dementia, the major psychoses, and congenital malformation. It is also likely that we may learn how to "block" one or more of the consequences of the multiple mutations that underlie common tumours. The molecular sciences will undoubtedly provide us with a battery of new diagnostic and pharmaceutical agents and many other exciting therapeutic possibilities. In short, molecular biology will enrich clinical practice, ${ }^{6}$ though the timescale may be considerably longer than its protagonists have claimed.

Does all this add up to early retirement for more clinically oriented medical research workers? On the contrary, early successes in molecular medicine have emphasised that knowledge of the molecular pathology of a disease is only the starting point in understanding the complex phenotypes that we see in our patients. For example, most single gene disorders result from many different mutations; relating them to the variable clinical features of these conditions entails expertise right across the medical sciences. Such a multidisciplinary approach will be even more important as we come to study polygenic conditions such as heart disease and the psychoses. Recombinant DNA technology is turning up a baffling array of biological mediators, lymphokines, growth factors, and the like. The assessment of their role in clinical practice will require all the skills of classic physiology and pharmacology.

Epidemiology will continue to pave the way in preventive medicine, but in future it will also provide clues as to where molecular biologists might look for the cause of the common killers of Western society. And, no less important, it will be necessary to continue to develop health service research and less glamorous areas of investigation, including medical decision making and audit. Just as our clinical departments will have to take on the molecular sciences, now that more solid methods are becoming available to analyse decision making and outcomes in clinical practice, they will also have to encompass these increasingly important aspects of medical research.

Viewed in this way, the medical sciences form a continuum, starting at the molecular level, through whole organ pathophysiology, to patients themselves and the environments in which they live. In thinking about how these diverse research activities might be organsied in clinical departments a central question is whether the basic medical sciences should be left to full time scientists, while clinicians concentrate on their application, or whether clinical investigators will have to take on an increasing amount of basic research.

\section{Interaction between basic and clinical sciences}

First highlighted by the classic study of Comroe and Dripps,' who found that many of the important advances in cardiovascular medicine had arisen from curiosity driven science that had set out to ask questions totally unrelated to their practical outcome, there are many examples of how clinical practice has fed on the basic sciences. Penicillin was discovered only after years of work in microbiology, starting in the brewing industry and followed by fundamental research on bacterial cell walls. And the major discoveries of the recombinant DNA era-the structure of DNA, the genetic code, gene cloning, restriction enzymes, and the rest -also stemmed from work in the basic sciences, most of which was not initiated with any practical application in mind.

But in the present context it is equally important to trace the origins of the success stories of molecular medicine over the past decade. Most stemmed from departments in clinical schools and from medically trained workers; in some cases the scientists concerned were still active in clinical practice. This work has not, with a few exceptions, entailed the development of completely new concepts or technology, but rather it reflects the application of tools developed by the basic biological sciences to the solution of problems of human pathology. It follows, therefore, that the basic sciences should be left to pursue research largely

\section{... medical research workers must learn the language and technology of the molecular sciences.}

driven by curiosity while medical research workers must learn the language and technology of the molecular sciences.

\section{Is it still possible to be a physician scientist?}

In his 1986 presidential address to the American Society for Clinical Investigation nobel laureate Joseph Goldstein described a new disease, PAIDS (Paralysed Academic Investigators Disease Syndrome). ${ }^{\circ}$ His patient, JR, was a 41 year old man who early in his career discovered the regenerating capacity of a crude rat liver extract, a finding which led to rapid academic advancement, many publications, and no further understanding of the nature of the putative growth factor over 12 fruitless years. In seeking the cause and treatment of PAIDS Goldstein compares JR's career with that of some of his (Goldstein's) medical scientist heroes, notably Garrod, Landsteiner, and Schoenheimer and concludes that JR's academic paralysis is the result of his unwillingness to take time away from clinical practice and committees to learn the basic scientific skills required to give him the ability and confidence to isolate and characterise the factor.

The lesson from this parable is clear. Given the complexities of modern biomedical science any young person who wishes to develop a career therein must be willing to set aside three or four years to learn the laboratory skills entailed. It is no use trying to achieve this goal by combining clinical work with laboratory research; while training to be a modern medical scientist it is essential to spend adequate time in full time research, just as it is equally important to 
concentrate on clinical activities during a period of clinical training.

\section{British scene}

Given these requirements before a young clinical investigator can hope to cope with the technical niceties of modern biological science, how might such a career be developed in a British setting? This important question encompasses the whole pattern of medical education and the future organisation of clinical academic departments.

Hopefully, as we evolve a more enlightened approach to curriculum planning many aspiring clinician scientists will be exposed to research while they are medical students, during intercalated degrees, $\mathrm{MD} / \mathrm{PhD}$ programmes, or at least by the provision of adequate elective time. Of course most students will want to become practising clinicians, and hence the main emphasis of the medical curriculum must be directed towards that end. But at the same time we must create an environment in which those with a genuine bent for more basic research can be encouraged in this direction early on in their careers.

Students of the future will require a solid grounding in biochemistry, cell and molecular biology, and the neurosciences, together with psychology, and, as they evolve, the behavioural and communication sciences. ${ }^{9}$ The other "preclinical sciences," particularly anatomy and whole organ physiology, could surely be taught in their clinical setting. This approach would shorten our undergraduate training, as it has in the United States and at the same time help to break down the artificial barriers between preclinical and clinical departments.

How might medical graduates develop careers as physician scientists? After qualifying they would spend a few years gaining further clinical experience and broadening their horizons, and, if necessary, obtaining a higher degree. Whether or not they had started their scientific training as students they would then break off from clinical training for several years and work full time in a research laboratory learning the tools of the trade. It is towards the end of this critical period that there must be a divergence of career pathways. A particularly gifted few will wish to pursue a full time career in basic medical science and not return to clinical practice. Apart from a few posts funded by the Medical Research Council, or charities, or those in university science departments, there are very few opportunities to pursue this type of career, a problem that requires urgent attention.

Most trainees will return to clinical practice for a few years and gain further training and accreditation in a particular specialty. By now they should have both the clinical and scientific self confidence to be able to develop a career in academic medicine in which they would build up a research team while carrying out a limited amount of clinical work in their chosen specialty. The encouragement of this second type of career is particularly important, for it is from among people with this breadth of skills that many of our future leaders in academic medicine will be drawn. They are not, as is sometimes suggested, half trained scientists and half baked clinicians. If they have undergone rigorous clinical and scientific training, and if they set their sights on a limited clinical topic, they are equipped to function in both worlds.

However, in our haste to improve the quality of training in the basic medical sciences we must not neglect the development of the skills required for more patient oriented clinical investigation or for health service research. Although more easily integrated into day to day clinical practice, this work requires time, technical skill, imagination, and an equal level of scientific stringency. Clinical research is not easy.
Questions are difficult to frame, measurements are often of necessity imprecise, and experimental subjects unpredictable, a fact not always appreciated by basic scientists; Escherichia coli genetics is rarely confused by glamorous milkmen.

The training of physician scientists to achieve excellence in clinical and epidemiological research is therefore no less demanding than that required of those who wish to pursue the basic sciences. It also requires uncluttered time, rigorous scientific discipline, and the possibility of an accelerated path to specialist accreditation.

\section{The training of physician-scientists is no less demanding than that of those who wish to pursue the basic sciences.}

I realise that these career pathways will not please those who believe that no one should achieve the status of an accredited specialist without 10 years or more of apprenticeship. When it is pointed out that it takes less than half this time in the United States the lame response is that clinical standards are much higher in the United Kingdom. I know of no evidence that this is true. It is difficult to believe that the protracted periods of time spent in junior hospital grades in the United Kingdom can be accounted for by anything but professional or political convenience. Is it really logical to demand an identical training programme for young people who are planning to spend their careers in full time practice and those who wish to divide their time between the research laboratory and limited clinical work in a tightly defined field?

\section{Academic clinical departments of the future}

But none of this will be any use unless those who have subjected themselves to these long and demanding apprenticeships can look forward to careers and facilities in academic clinical departments which will enable them to use their skills. We will have to provide an appropriate environment for the basic sciences and yet maintain expertise in more conventional clinical investigation and health service research. How can these diverse requirements be encompassed while at the same time maintaining standards in clinical practice and teaching?

British clinical academic departments are much too small to achieve these ends, and there must be some expansion of space and staffing, a message which we must somehow communicate to government. But though more adequate funding is essential, we can help ourselves by some reorganisation of our research facilities. Molecular and cell biology are breaking down artificial barriers between clinical disciplines, and cardiologists and psychiatrists are now using similar technology to solve their particular problems. But this work is expensive and requires professionally run laboratories staffed by a mixture of clinical and basic scientists. It will not be feasible to provide these facilities for every clinical department. A possible solution, one we are experimenting with in Oxford, is to develop a central research facility for groups from different clinical departments that is large enough to house a critical mass of basic science and where clinical scientists can be trained and carry out research $i$. 1 their particular specialties. Centres of this kind are attractive to non-clinical scientists; scientific isolation is a major bar to recruitment of top class scientists to clinical 
departments. And sharing equipment and expertise offers a more economical way of developing basic science in medical schools. Most importantly, such integrated research centres act as a focus for strengthening collaborative relations between clinical and basic science departments, a major goal if we are to make the best use of the new developments in the molecular sciences.

But the organisational problems of carrying out good basic science in clinical departments, complex though they are, may pale into insignificance when we consider how at the same time we can maintain adequate facilities for clinical research, given the virtual collapse of the dual support system and the pressures that will undoubtedly fall on the wards and outpatients of teaching hospitals once the marketplace economy of the health service reorganisation starts to bite. Here again we shall have to tackle problems which academic medicine has never faced before. How much does it add to our ward and outpatient costs to pursue clinical research? Will budgetholding general practitioners refer patients on research protocols? Who will pay for the visits? How can these activities be protected while our administrators, most of whom don't understand their importance, are interested only in a cost effective service to offer in a competitive market place? The days when the integration of clinical practice, teaching, and research could be taken for granted as the duty of a teaching hospital are over.

How can academic medicine respond to this threat to its future? Perhaps only by trying to do what it has always aspired to-that is, by setting standards. In the context of the reforms in health care this means taking a major lead in developing the "new" clinical sciences of audit, research on outcomes, information systems, and so on. If the changes in the pattern of patient care are to take place as envisaged by government, our university departments must see to it that these changes are properly monitored. And departments must not be afraid to say when they think that the changes are ill conceived or require further evaluation by well designed studies. The rush to gain hospital trust status by some of our leading teaching centres before there was any possibility of assessing the effect on teaching and research emphasises the precarious state of academic medicine in the United Kingdom and the danger of jeopardising its future for the sake of short term political expediency.

\section{Physician scientists of the future}

Though the world is undoubtedly more complex than it was in Osler's time, the basic functions of clinical academic departments that he envisaged have not changed. Such departments must set clinical standards, teach, and pursue research at a high standard. Because of the complexity of modern science they will have to have more staff who devote most of their time to the bench than in the past. It follows, therefore, that they will have to be larger and organised more professionally. But given the equal complexity of the delivery of medical care, I doubt whether the future leaders of such departments can, or should, be full time laboratory scientists. Rather, they should have been exposed to periods of rigorous training in a basic science or clinical research laboratory so that they can provide the environment in which others can pursue good science. And at the same time they must have the breadth of vision to enable them to encourage excellence in clinical practice and medical education and hence to integrate the increasingly diverse activities required of clinical academic departments of the future.
The physician scientist is not, therefore, an extinct species, but rather one that will have to diversify to survive. In future it must encompass full time bench workers, hybrids of clinician and scientist, clinicians who critically evaluate the delivery of health care, and those whose main role is to evaluate undergraduate and postgraduate education and to ensure that it is not neglected in the effort to achieve excellence in clinical practice and research. The organisation of a group of people with such disparate skills into a functional department will not be easy, and it is here that the major challenge to physician scientists of the future lies. But as medical research moves into the most exciting phase of its development it is one that is well worth taking on.

To have any chance of success there will have to be a major effort to educate government about the complexities of modern academic medicine and why there is an urgent need to improve the staffing and facilities of our university clinical departments. In addition, we shall have to protect our clinical research facilities as we enter the health service market place; they are the most vulnerable part of the activity of our teaching hospitals. Medical schools must, in turn, look to their own organisation and see how these increasing demands on their skills can best be organised and how, by breaking down old departmental barriers, they can take on the complexities of modern science most efficiently. And, most importantly, we shall have to relook at undergraduate and postgraduate education and determine how we can facilitate the career development of the particularly talented young people who will be needed to make the whole thing work.

It is unfortunate that the need to re-evaluate the future of academic medicine coincides with an upheaval in the organisation of health care. But as these activities are inseparable it is a challenge that must be met.

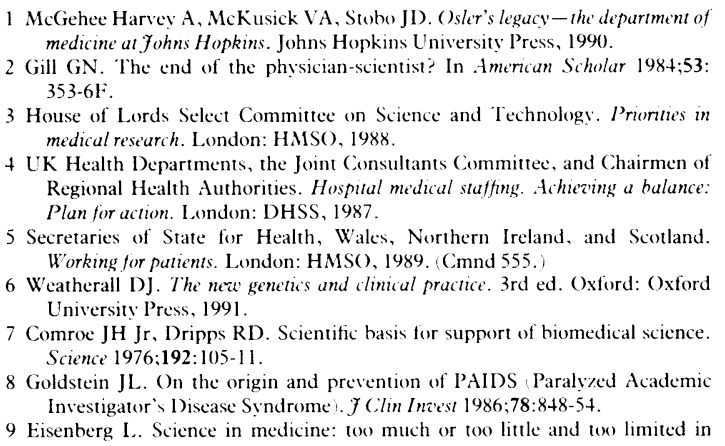

Accepted 19 February 1991

\section{ANY QUESTIONS}

Are there any hazards to the regular use of chamomile for infants or adults?

Chamomile is an essential oil used either as an infusion of chamomile flowers or as an ointment. I am not aware of any harmful effects of regular intake of chamomile tea. Topical application may occasionally cause contact sensitivity, and anaphylaxis has apparently been reported rarely. - LINDA BEELEY, director, drug and therapeutics unit, Birmingham

Reynolds JEF, ed. Martindale: the extra pharmacopoeia. 29th ed. London: Pharmaceutical Press, 1989:1061. 